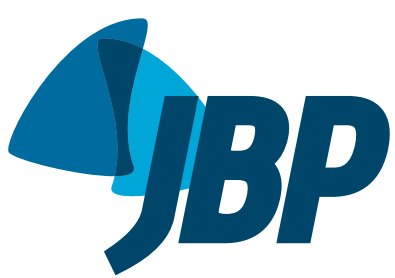

1. Departamento de Cirurgia Torácica Instituto do Coração, Hospital das Clínicas, Faculdade de Medicina da Universidade de São Paulo - InCor/HCFMUSP - São Paulo (SP) Brasil.

Submitted: 29 April 2015. Accepted: 4 August 2015.

Study carried out in the Departamento de Cirurgia Torácica, Instituto do Coração, Hospital das Clínicas, Faculdade de Medicina da Universidade de São Paulo InCor/HC-FMUSP - São Paulo (SP) Brasil.

\title{
Ex vivo lung perfusion in Brazil
}

Luis Gustavo Abdalla', Karina Andrighetti de Oliveira Braga', Natalia Aparecida Nepomuceno', Lucas Matos Fernandes', Marcos Naoyuki Samano ${ }^{1}$, Paulo Manuel Pêgo-Fernandes ${ }^{1}$

\begin{abstract}
Objective: To evaluate the use of ex vivo lung perfusion (EVLP) clinically to prepare donor lungs for transplantation. Methods: A prospective study involving EVLP for the reconditioning of extended-criteria donor lungs, the criteria for which include aspects such as a $\mathrm{PaO}_{2} / \mathrm{FiO}_{2}$ ratio $<300 \mathrm{mmHg}$. Between February of 2013 and February of 2014, the lungs of five donors were submitted to EVLP for up to $4 \mathrm{~h}$ each. During EVLP, respiratory mechanics were continuously evaluated. Once every hour during the procedure, samples of the perfusate were collected and the function of the lungs was evaluated. Results: The mean $\mathrm{PaO}_{2}$ of the recovered lungs was $262.9 \pm 119.7 \mathrm{mmHg}$ at baseline, compared with $357.0 \pm 108.5 \mathrm{mmHg}$ after $3 \mathrm{~h}$ of EVLP. The mean oxygenation capacity of the lungs improved slightly over the first $3 \mathrm{~h}$ of EVLP-246.1 $\pm 35.1,257.9$ \pm 48.9 , and $288.8 \pm 120.5 \mathrm{mmHg}$ after 1,2 , and $3 \mathrm{~h}$, respectively-without significant differences among the time points $(p=0.508)$. The mean static compliance was $63.0 \pm$ $18.7 \mathrm{mmHg}, 75.6 \pm 25.4 \mathrm{mmHg}$, and $70.4 \pm 28.0 \mathrm{mmHg}$ after 1,2 , and $3 \mathrm{~h}$, respectively, with a significant improvement from hour 1 to hour $2(p=0.029)$ but not from hour 2 to hour 3 ( $p=0.059$ ). Pulmonary vascular resistance remained stable during EVLP, with no differences among time points $(p=0.284)$. Conclusions: Although the lungs evaluated remained under physiological conditions, the EVLP protocol did not effectively improve lung function, thus precluding transplantation.
\end{abstract}

Keywords: Lung transplantation; Organ preservation; Brain death; Donor selection.

\section{INTRODUCTION}

Ex vivo lung perfusion (EVLP) is a novel strategy for reconditioning lungs, with a view to increasing the number of viable organs for transplantation and to reducing the mortality of patients awaiting a transplant. ${ }^{(1-3)}$ The principle of the technique is to replicate the physiological environment that provides the substrates needed to maintain cell metabolism.

Initially, EVLP was described by Steen et al. ${ }^{(3)}$ for the evaluation of non-heart-beating donor lungs, and, subsequently, it was modified for application to the reconditioning of extended-criteria donor lungs by the Toronto Lung Transplant Group, in Canada. ${ }^{(4)}$ Lung reconditioning with subsequent transplantation has been employed by various transplant groups, with positive outcomes. Cypel et al. (2) reported on a series of 20 reconditioned extended-criteria donor lungs in which the $\mathrm{PaO}_{2} / \mathrm{FiO}_{2}$ ratio increased significantly at the end of the reconditioning process (2-4 h). Those authors found that the rate of primary graft dysfunction $72 \mathrm{~h}$ after transplantation was comparable for both recipients of EVLP lungs and recipients of conventionally selected lungs, and that no adverse events were directly attributable to EVLP. In other centers, such as those in Vienna (Austria), Paris (France), and Turin (Italy), the outcomes were similar to those obtained by the Toronto group..$^{(5)}$ Despite the positive outcomes, in the United Kingdom, a study showed that, of 13 reconditioned lungs, only 6 were transplanted, which represents a utilization rate of $46 \%$. ${ }^{(6)}$
The present article reports on the use of EVLP clinically to prepare donor lungs for transplantation in Brazil.

\section{METHODS}

The study was approved by the Brazilian National Health Council-Comissão Nacional de Ética em Pesquisa (CONEP, Brazilian National Research Ethics Committee; Registration No. 16026; Process No. 25000.113350/2010-46). We used human brain-dead donor lungs that were rejected for conventional transplantation because their $\mathrm{PaO}_{2} / \mathrm{FiO}_{2}$ ratio was $<300 \mathrm{mmHg}$. Between February of 2013 and February of 2014, there were five lung recoveries for the lung reconditioning protocol. Immediately before recovery, bronchoscopic inspection with BAL was performed. The BAL procedure involved instillation of $40 \mathrm{~mL}$ of sterile saline ( $0.9 \%$ sodium chloride) into the segments of the basal pyramid of the right lower lobe, followed by aspiration until approximately $50 \%$ of the instilled amount was recovered and stored in a collection vial. Lung recovery was performed as usual for conventional transplantation. The lungs were perfused with Perfadex ${ }^{\circledR}$ (Vitrolife, Göteborg, Sweden) as the preservation solution, stored at $4^{\circ} \mathrm{C}$ in a special bag, and sent to the Heart Institute Surgery Center of the University of São Paulo School of Medicine Hospital das Clínicas, in the city of São Paulo, Brazil, to undergo the procedure.

The pulmonary artery and pulmonary veins were sutured onto special plastic cannulas, and the lung block was placed in a perfusion chamber (XVIVO Perfusion, Göteborg, 
Sweden). The perfusion system consists of cannulas, a membrane deoxygenator, a heat exchanger, a leukocyte filter, and a centrifugal pump (Maquet, Toronto, Canada). The system is primed with $1.5 \mathrm{~L}$ of Steen Solution ${ }^{\circledR}$ (Vitrolife), 500 mg methylprednisolone, 500 mg/500 $\mathrm{mg}$ imipenem/cilastatin sodium, and heparin (3,000 IU). The established flow corresponded to $40 \%$ of the cardiac output during ventilation at physiological levels: a tidal volume $\left(\mathrm{V}_{\mathrm{T}}\right)$ of $6 \mathrm{~mL} / \mathrm{kg}$; a respiratory rate of 7 breaths/min; a positive end-expiratory pressure of $5 \mathrm{cmH}_{2} \mathrm{O}$; and an $\mathrm{FiO}_{2}$ of $21 \%$. For flow increase, as well as for reheating and ventilation, we followed the protocol described by Cypel et al. ${ }^{(7)}$

Perfusion time was set at $4 \mathrm{~h}$, and ventilatory and pulmonary gas exchange parameters were evaluated at the end of each hour. At the end of hour 3, perfusion was interrupted in the lungs with no prospects of improvement in lung function or respiratory mechanics with a view to transplantation. At evaluation, the ventilator was set at a $V_{T}$ of $10 \mathrm{~mL} / \mathrm{kg}$ of body weight, a respiratory rate of 10 breaths/min, a positive end-expiratory pressure of $5 \mathrm{~cm} \mathrm{cmH}_{2} \mathrm{O}$, and an $\mathrm{FiO}_{2}$ of $100 \%$. A sample of the perfusate was collected from the outlet of the pulmonary artery and pulmonary vein for blood gas analysis, which measured $\mathrm{PaCO}_{2}$, mixed venous carbon dioxide tension, $\mathrm{PaO}_{2}$, mixed venous oxygen tension, lactate levels, and glucose levels. Ventilatory parameters measured included peak pressure, plateau pressure, mean airway pressure, static compliance, and $\mathrm{V}_{\mathrm{T}^{*}}$. Mean pulmonary artery pressure and perfusion flow were also measured.

The left lower lobe was sampled before and immediately after EVLP. The samples were fixed in $10 \%$ formalin for $24 \mathrm{~h}$, embedded in paraffin, sectioned on a microtome into $5 \mu \mathrm{m}$ thick slice, and stained with H\&E. The presence/absence of pathological changes was investigated under light microscopy by a pathologist.

\section{Descriptive statistics}

Quantitative data are expressed as means and standard deviations. For each variable, the assumption of normal distribution was tested with the Shapiro-Wilk test. Categorical variables are expressed as frequencies.

\section{Inferential statistics}

For comparison of means, we used repeated measures ANOVA and the paired Student's t-test. The probability of a type I (a) error was set at 0.05 for all inferential analyses.

Descriptive and inferential statistics were calculated using the SPSS Statistics software package, version 21 (IBM Corporation, Armonk, NY, USA).

\section{RESULTS}

The lungs of five donors were submitted to EVLP at the Heart Institute Surgery Center. However, no transplants were performed, because none of the lungs met the functional criteria for transplantation.
Four male donors and one female donor were used, and the mean length intubation was 5.6 days. All lungs were obtained from brain-dead donors, because the current legislation in Brazil does not allow the use of non-heart-beating donors. The most common cause of death was traumatic brain injury, followed by subarachnoid hemorrhage. The reason the donor lungs were rejected for conventional transplantation was poor blood gas values $\left(\mathrm{PaO}_{2} / \mathrm{FiO}_{2}\right.$ ratio $\left.=100 \%\right)$. In three cases, discard was associated with radiological changes, and in two cases in which the $\mathrm{PaO}_{2} / \mathrm{FiO}_{2}$ ratio was satisfactory, the lungs were discarded either because of indefinite histology for brain neoplasm (this being the cause of brain death) or because the poor clinical condition of the recipient precluded transplantation (Table 1).

The mean oxygenation capacity $\left(\Delta \mathrm{PO}_{2}\right)$ measured during EVLP showed little variation, with no statistically significant differences (Figure 1). After 1, 2, and $3 \mathrm{~h}$ of EVLP, respectively, $\triangle \mathrm{PO}_{2}$ values were $246.1 \pm 35.7$ $\mathrm{mmHg}, 257.9 \pm 48.9 \mathrm{mmHg}$, and $288.8 \pm 120.5 \mathrm{mmHg}$ (Figure 1). A comparison of the $\triangle \mathrm{PO}_{2}$ values measured at recovery with those observed at the end of EVLP showed that, although the final mean $\Delta \mathrm{PO}_{2}$ was higher, there were no statistically significant differences (Figure 1). The mean $\mathrm{PaO}_{2}$ of the recovered lungs was 262.9 $\pm 119.7 \mathrm{mmHg}$ at baseline, compared with $357.0 \pm$ $108.5 \mathrm{mmHg}$ after $3 \mathrm{~h}$ of EVLP.

The mean static compliance after 1,2 , and $3 \mathrm{~h}$, respectively, was $63.0 \pm 18.7 \mathrm{mmHg}, 75.6 \pm 25.4$ $\mathrm{mmHg}$, and $70.4 \pm 28.0 \mathrm{mmHg}$, with a significant difference in results between hour 1 and hour 2 ( $p=$ 0.029).In most of the EVLP procedures, the perfusion time was 180 minutes; in only one case was the perfusion time 240 minutes.

A comparative evaluation of the lung biopsy samples collected before and after EVLP showed that, in three cases, there was worsening of edema and formation of visible thrombi. The results of BAL examination revealed colonization by virulent bacteria with a high potential to cause pulmonary infection in three cases.

\section{DISCUSSION}

The EVLP technique has been disseminated worldwide, with positive outcomes at various centers. In 2013, research groups from Toronto, Vienna, and Paris presented their clinical results with EVLP at the International Society of Heart and Lung Transplantation Meeting. ${ }^{(5)}$ The results showed that the reconditioned lung utilization rate was high and that the rates of primary graft dysfunction within the first $72 \mathrm{~h}$ were low. In the USA, the technique has been validated in a multicenter clinical trial and approved by the Food and Drug Administration. (8)

Despite the clearly demonstrated advances, we found discrepancies among the centers regarding the EVLP lung utilization rate for transplantation. In the present study, we report the use of EVLP at our center. We performed five lung perfusions; however, EVLP was 
Table 1. Characteristics of the selected donors.

\begin{tabular}{cccccc} 
Gender & Age, years & Cause of death & $\mathbf{M V}$, days & $\mathbf{P a O}_{\mathbf{2}}, \mathbf{m m} \mathbf{H g}^{\mathbf{a}}$ & Donor \\
M & 18 & TBI & 3 & 264,0 & 1 \\
F & 50 & SAH & 7 & 283,0 & 2 \\
M & 19 & TBI & 3 & 62,5 & 3 \\
M & 41 & TBI & 6 & 334,6 & 4 \\
M & 29 & SAH & 9 & 370,6 & 5 \\
\hline
\end{tabular}

MV: mechanical ventilation; $M$ : male; F: female; TBI: traumatic brain injury; and SAH: subarachnoid hemorrhage.

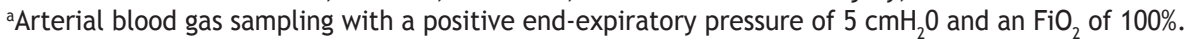

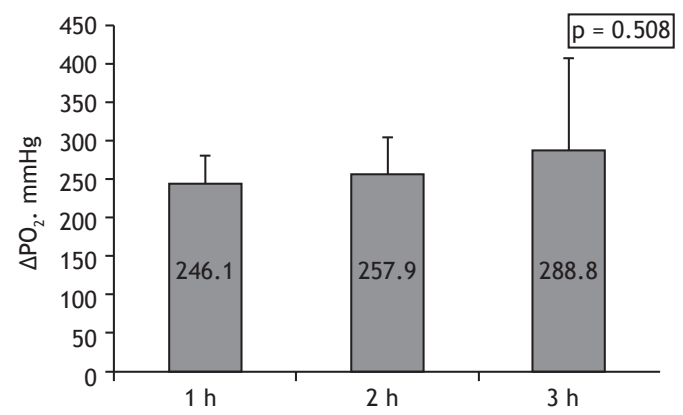

Figure 1. Evolution of $\triangle \mathrm{PO}_{2}\left(\mathrm{PaO}_{2}-\mathrm{PvO}_{2}\right)$ throughout ex vivo perfusion. There were no statistically significant differences among the three time points evaluated ( $1 \mathrm{~h}, 2$ $\mathrm{h}$, and $3 \mathrm{~h}$ after the initiation of ex vivo perfusion).

unable to improve lung function because, in general, the recovered lungs showed pronounced physiological changes upon arrival at our surgery center.

Several factors may be related to the limited number of lung recoveries for EVLP in Brazil. In our country, organs are obtained only from brain-dead donors. This limitation leads to there being a small supply of lungs for EVLP, in comparison with the mean rates of other centers where lungs from non-heart-beating donors are used. Cypel et al. reported that $44 \%$ of 50 non-heart-beating donor lungs subjected to EVLP were used for transplantation in Toronto. ${ }^{(1)}$

The use of lungs from non-heart-beating donors is well established in the literature, and related data have been compiled into the International Society of Heart and Lung Transplantation registry, showing that the use of such lungs results in an increase in the number of transplants. In addition, a multicenter study reported that the outcomes of transplantation of lungs from non-heart-beating donors were similar to those of transplantation of lungs from brain-dead donors, suggesting that transplant teams should make continuous efforts to increase the number of transplants using non-heart-beating donors. ${ }^{(9)}$

In our sample, poor blood gas values alone were not the primary cause of donor rejection. The most common reason for donor rejection in 2013 was infection (in $35 \%$ ), followed by morbidity history (in $16.7 \%$ ), including smoking and use of inhaled drugs, and blood gas changes (in 15.6\%).

The EVLP lung utilization rate for transplantation varies among the transplant centers that use the EVLP technique. The research groups in Lund (Sweden) and in Toronto are the most successful, with utilization rates of $67 \%$ and $87 \%$, respectively. However, the Newcastle group, in the United Kingdom, reported a utilization rate of $46 \%$ and attributed it to complications related to the quality of the recovered lungs. Like the Newcastle group, we extended the criteria for donor lung recovery, including those with blood gas changes associated with edema and contusion.(6) Certainly the limited number of perfusions performed by our group and the inclusion of donor lungs with poor blood gas values associated with other changes had a significant impact on our utilization rate. The use of extended-criteria donor lungs resulted in a greater likelihood of dysfunctions, such as infection, alveolar infiltrate, excess secretions, and pulmonary embolism, compromising the EVLP reconditioning process. The main radiological findings were pulmonary infiltrate (contusion or congestion) and infection, confirmed by H\&E histology and BAL culture at the end of EVLP. The comorbidities detected in three lungs by radiological imaging and histopathological analysis before EVLP may have negatively impacted reconditioning, given that the functional activity of those lungs did not progress satisfactorily. In addition, histological analysis of the lung tissue at the end of perfusion showed increased edema, thrombus formation, and other vascular changes in these cases. In the fourth case, in which there were mild radiological and histopathological changes, EVLP occurred satisfactorily, increasing lung functional indices up to values close to the acceptable threshold for transplantation. Regarding growth in BAL cultures, we detected colonization by virulent bacteria, with a high potential to cause pneumonia in recipients with suppurative disease, in three donors. At our center, previous studies reported high rates of BAL culture positivity in lung donors. A retrospective study reported that, of 49 lungs recovered for conventional transplantation, 31 had positive cultures, mainly for Staphylococcus aureus and Pseudomonas aeruginosa. (10) Our database provides evidence that the current situation remains unchanged, given that, in 2013, 26 of the 27 lungs recovered for conventional transplantation had positive cultures. This underscores the importance of investigation of the specific characteristics of the donors at each center so that possible remedial action can be taken before the use of EVLP. Postoperative complications related to the development of pneumonia can be prevented by combining EVLP and specific prophylactic antibiotic regimens. In one of the cases reported here, we found, on the basis of histopathological 
results, that the donor had bronchiectasis. In another case, a relevant finding on microscopic examination was the presence of microthrombi. Both bronchiectasis and microthrombi had been missed on imaging. In the two cases, although EVLP was not satisfactory enough for the reconditioning process, it was important in the diagnosis of the comorbidities. We deem it necessary to use additional imaging modalities, such as CT, as well as early fiberoptic bronchoscopy to minimize the number of pathologically compromised donor lungs.

In a case report, Machuca et al. reported the use of EVLP for the treatment of lungs from a donor with pulmonary thromboembolism, with the addition of a thrombolytic agent to the perfusate, which resulted in improvement in the lungs and subsequent transplantation. ${ }^{(11)}$ In an experimental study conducted by our team, we found a significant improvement in arterial blood gas values after $1 \mathrm{~h}$ of EVLP. ${ }^{(12,13)}$ However, we highlight some methodological differences relative to the present study, such as the use of an $\mathrm{FiO}_{2}$ of $100 \%$ throughout perfusion and the use of an open left atrium.

In recent years, EVLP has proven to be very important in the rehabilitation of extended-criteria donor lungs, increasing the number of transplants performed. Often, the severity of the comorbidities inherent in the donor lung has a major impact on the achievement of positive outcomes from the use of the EVLP technique. Among the various organ procurement centers, there are differences with regard to donor care protocols, that is, there is no consensus regarding thyroid hormone replacement, use of desmopressin (an antidiuretic hormone analog that has mild vasopressor activity), or use of a feeding tube.

During the development of our protocol, we found that donor lungs in Brazil have a higher rate of complications after brain death than do those available for reconditioning at other centers. The here reported non-utilization of EVLP donor lungs for transplantation suggests the need for investigation of the specific characteristics of the donors at our center. Such information may be highly relevant to making adjustments to the reconditioning technique so as to meet specific needs more fully, thus increasing the likelihood of success with EVLP.

Therefore, we conclude that, although the EVLP technique used at our center contributed to maintaining the lungs under physiological conditions, it did not effectively improve lung function, thus precluding the use of the lungs for transplantation.

\section{REFERENCES}

1. Cypel M, Yeung JC, Machuca T, Chen M, Singer LG, Yasufuku K et al. Experience with the first 50 ex vivo lung perfusions in clinical transplantation. J Thorac Cardiovasc Surg. 2012;144(5):1200-6. http://dx.doi.org/10.1016/j.jtcvs.2012.08.009

2. Cypel M, Yeung JC, Liu M, Anraku M, Chen F, Karolak W, et al Normothermic ex vivo lung perfusion in clinical lung transplantation. N Engl J Med. 2011;364(15):1431-40. http://dx.doi.org/10.1056/ NEJMoa1014597

3. Steen S, Sjöberg T, Pierre L, Liao Q, Eriksson L, Algotsson L. Transplantation of lungs from a non-heart-beating donor. Lancet. $\quad 2001 ; 357(9259): 825-9$. http://dx.doi.org/10.1016/S01406736(00)04195-7

4. Cypel M, Rubacha M, Yeung J, Hirayama S, Torbicki K, Madonik $\mathrm{M}$, et al. Normothermic ex vivo perfusion prevents lung injury compared to extended cold preservation for transplantation. Am J Transplant. 2009;9(10):2262-9. http://dx.doi.org/10.1111/j.16006143.2009.02775.x

5. Machuca TN, Cypel M. Ex vivo lung perfusion. J Thorac Dis. 2014;6(8):1054-62

6. Zych B, Popov AF, Stavri G, et al. Early outcomes of bilateral sequential single lung transplantation after ex-vivo lung evaluation and reconditioning. J Heart Lung Transplant. 2012;31(3):274-81. http://dx.doi.org/10.1016/j.healun.2011.10.008

7. Cypel M, Yeung JC, Hirayama S, Rubacha M, Fischer S, Anraku M et al. Technique for prolonged normothermic ex vivo lung perfusion. J Heart Lung Transplant. 2008;27(12):1319-25. http://dx.doi.

org/10.1016/j.healun.2008.09.003

8. Sanchez PG, Davis RD, D'Ovidio F, Cantu E, Weyant M, Camp P, et al. The NOVEL lung trial one-year outcomes. J Heart Lung Transplant. 2014;33(4):S71-S72. http://dx.doi.org/10.1016/j.healun.2014.01.226

9. Cypel M, Levvey B, Van Raemdonck D, Erasmus M, Love R, Mason $D$, et al. Favorable outcomes of donation after cardiac death in lung transplantation: a multicenter study. J Heart Lung Transplant. 2013;32(4):S15. http://dx.doi.org/10.1016/j.healun.2013.01.017

10. Campos S, Caramori M, Teixeira R, Afonso J Jr, Carraro R, Strabelli $T$, et al. Bacterial and fungal pneumonias after lung transplantation. Transplant Proc. 2008;40(3):822-4. http://dx.doi.org/10.1016/j. transproceed.2008.02.049

11. Machuca TN, Hsin MK, Ott HC, Chen M, Hwang DM, Cypel M, et al. Injury-specific ex vivo treatment of the donor lung: pulmonary thrombolysis followed by successful lung transplantation. Am J Respir Crit Care Med. 2013;188(7):878-80. http://dx.doi.org/10.1164/ rccm.201302-0368LE

12. Pêgo-Fernandes PM, Mariani AW, Medeiros IL, Pereira AE, Fernandes FG, Valle Unterpertinger Fd, et al. Ex vivo lung evaluation and reconditioning. Rev Bras Cir Cardiovasc. 2010;25(4):441-6. http:// dx.doi.org/10.1590/S0102-76382010000400006

13. Medeiros IL, Pêgo-Fernandes PM, Mariani AW, Fernandes FG, do Vale Unterpertinger $F$, Canzian $M$, et al. Histologic and functional evaluation of lungs reconditioned by ex vivo lung perfusion. J Heart Lung Transplant. 2012;31(3):305-9. http://dx.doi.org/10.1016/j. healun.2011.10.005 